\title{
Commentary: Relentless disease, relentless measures: Treat recurrent pulmonary vein obstruction early and often
}

\author{
Joseph B. Clark, MD
}

The constellation of total anomalous pulmonary venous connection (TAPVC), heterotaxy, a single ventricle, and primary pulmonary venous obstruction has long been recognized as an unfortunate set of cards. ${ }^{1}$ Although some series have shown improving surgical outcomes over time, others have not. ${ }^{2,3}$ Nevertheless, despite the challenges of this difficult and sometimes recalcitrant form of congenital heart disease, the battle wages on in pursuit of better patient survival.

Spigel and colleagues ${ }^{4}$ present a large, single-institution series of patients with TAPVC, focusing on the influence of heterotaxy and preoperatively obstructed venous connection on subsequent mortality and recurrent obstruction. Compared with those without heterotaxy, TAPVC patients with heterotaxy demonstrated significantly worse survival, although much of this disparity may be attributed to the high incidence $(90 \%)$ of single-ventricle anatomy within the heterotaxy group. Not surprisingly, overall survival was higher for TAPVC patients with 2 ventricles rather than single-ventricle anatomy ( $94 \%$ vs $63 \%$ ).

Recurrent pulmonary vein obstruction represented another risk factor for mortality. As reported previously, ${ }^{5,6}$ recurrent vein disease predominantly presented within the first year after surgery. Similar to another study that identified heterotaxy, a single ventricle, and primary obstruction as risk factors for recurrent obstruction, ${ }^{6}$ this report showed primary

From the Division of Pediatric Cardiac Surgery, Department of Pediatrics, Penn State Children's Hospital, Hershey, Pa.

Disclosures: The author reported no conflicts of interest.

The Journal policy requires editors and reviewers to disclose conflicts of interest and to decline handling or reviewing manuscripts for which they may have a conflict of interest. The editors and reviewers of this article have no conflicts of interest.

Received for publication March 27, 2021; revisions received March 27, 2021; accepted for publication March 29, 2021; available ahead of print April 2, 2021.

Address for reprints: Joseph B. Clark, MD, Division of Pediatric Cardiac Surgery, Department of Pediatrics, Penn State Children's Hospital, 500 University Dr, H085, Hershey, PA 17033 (E-mail: jclark7@ pennstatehealth.psu.edu).

J Thorac Cardiovasc Surg 2022;163:396-7

$0022-5223 / \$ 36.00$

Copyright (c) 2021 by The American Association for Thoracic Surgery

https://doi.org/10.1016/j.jtcvs.2021.03.094
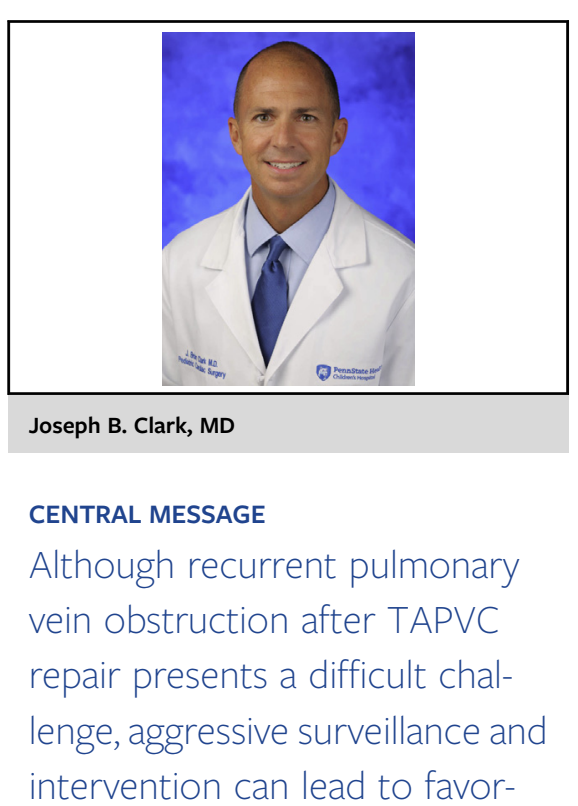

able outcomes.

obstruction with either heterotaxy or a single ventricle to be associated with increased pulmonary vein interventions. Notably, the need for pulmonary vein intervention was a marker for decreased survival. According to institutional practice, patients with heterotaxy and a single ventricle underwent more frequent surveillance, a bias that may have contributed to more interventions for these patients. However, this concern is mitigated by the observation that both heterotaxy and single-ventricle patients without primary obstruction did not experience increased interventions.

Perhaps the most interesting aspect of this study involves the outcomes of intervention for recurrent pulmonary vein obstruction. If there is a potential silver lining, it may be that disease recurrence appears to be fairly quiescent beyond the first year, resulting in a flattened curve that yielded a steady state for most patients. ${ }^{4}$ If detected and treated early and often, the fire of pulmonary vein disease can, in many patients, be eventually extinguished. Unfortunately, this success is not universal. For patients experiencing recurrent disease, each successive round resulted in increasingly worse (shorter) reintervention-free survival, suggesting the pathologic obstructive process was accelerating rather than slowing.

Accordingly, Spigel and colleagues ${ }^{4}$ recommend intense surveillance and intervention. With such a policy, they suggest that most patients can be rescued from the cycle of recurrent vein obstruction. Previously, in light of the relentless nature of the obstructive process and associated dismal 
prognosis, ${ }^{7}$ some may have considered such aggressive care with multiple reoperations to be futile or unwarranted, a sentiment that may have hindered the opportunity for repeat surgery in some cases. This study appears to argue instead for an escalation of care and for a greater willingness to perform serial operations; it advocates for staying in the fight. Hippocrates long ago counseled that extreme disease calls for extreme measures. ${ }^{8}$ In this case, relentless disease may call for relentless measures.

\section{References}

1. Gaynor JW, Collins MH, Rychik J, Gaughan JP, Spray TL. Long-term outcome of infants with single ventricle and total anomalous pulmonary venous connection. $J$ Thorac Cardiovasc Surg. 1999;117:506-14.

2. Lahiri S, Wang Y, Caldarone CA, Morris SA. Trends in infant mortality after TAPVR repair over 18 years in Texas and impact of hospital surgical volume. $\mathrm{Pe}$ diatr Cardiol. 2020;41:77-87.
3. Khan MS, Bryant R, Kim SH, Hill KD, Jacobs JP, Jacobs ML, et al. Contemporary outcomes of surgical repair of total anomalous pulmonary venous connection in patients with heterotaxy syndrome. Ann Thorac Surg. 2015;99: 2134-40.

4. Spigel ZA, Edmunds EE, Caldarone CA, Hickey EJ, Binsalamah ZM Heinle JS. Total anomalous pulmonary venous connection: influence of heterotaxy and venous obstruction on outcomes. J Thorac Cardiovasc Surg. 2022; 163:387-95.e3.

5. Seale AN, Uemura H, Webber SA, Partridge J, Roughton M, Ho SY, et al. Tota anomalous pulmonary venous connection: outcome of postoperative pulmonary venous obstruction. J Thorac Cardiovasc Surg. 2013;145:1255-62.

6. White BR, Ho DY, Faerber JA, Katcoff H, Glatz AC, Mascio CE, et al. Repair of total anomalous pulmonary venous connection: risk factors for postoperative obstruction. Ann Thorac Surg. 2019;108:122-9.

7. Caldarone CA, Najm HK, Kadletz M, Smallhorn JF, Freedom RM, Williams WG, et al. Relentless pulmonary vein stenosis after repair of total anomalous pulmonary venous drainage. Ann Thorac Surg. 1998;66:1514-20.

8. Ventura HO, Mehra MR, Messerili FH. Desperate diseases, desperate measures: tackling malignant hypertension in the 1950s. Am Heart J. 2001;142: 197-203.
See Article page 387

\section{Commentary: Total anomalous pulmonary venous connection, heterotaxy and pulmonary vein obstruction: The relentless pursuit of imperfection}

Anusha Jegatheeswaran, MD, PhD, FRCSC, ${ }^{\mathrm{a}}$ and Tara Karamlou, MD, MSc ${ }^{\mathrm{b}}$

Spigel and colleagues ${ }^{1}$ describe the medium-term outcomes among patients with total anomalous pulmonary venous connection (TAPVC) over nearly 25 years at their

\footnotetext{
From the ${ }^{a}$ Division of Cardiovascular Surgery, Department of Surgery, Hospital for Sick Children, University of Toronto, Toronto, Ontario, Canada; and ${ }^{\mathrm{b}}$ Division of Pediatric Cardiac Surgery, The Heart, Vascular, and Thoracic Institute, Cleveland Clinic, Cleveland, Ohio.

Disclosures: The authors reported no conflicts of interest.

The Journal policy requires editors and reviewers to disclose conflicts of interest and to decline handling or reviewing manuscripts for which they may have a conflict of interest. The editors and reviewers of this article have no conflicts of interest.

Received for publication April 9, 2021; revisions received April 9, 2021; accepted for publication April 12, 2021; available ahead of print April 19, 2021.

Address for reprints: Anusha Jegatheeswaran, MD, PhD, FRCSC, Division of Cardiovascular Surgery, Department of Surgery, Hospital for Sick Children, 555 University Ave, Toronto, Ontario, M5G 1X8 Canada (E-mail: anusha.jegatheeswaran @ utoronto.ca).

J Thorac Cardiovasc Surg 2022;163:397-8

0022-5223/\$36.00

Copyright $(2021$ Published by Elsevier Inc. on behalf of The American Association for Thoracic Surgery

https://doi.org/10.1016/j.jtcvs.2021.04.031
}

Check for updates

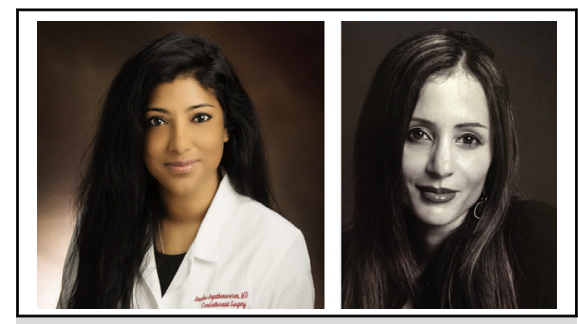

Anusha Jegatheeswaran, MD, PhD, FRCSC (left) and Tara Karamlou, MD, MSc (right)

\section{CENTRAL MESSAGE \\ Complex statistics can provide increased understanding of $\mathrm{CHD}$ patients but must be coupled with optimum research meth- odology to ensure we are not in relentless pursuit of an imperfect understanding.}

institution. Their objective was to examine time-related mortality and reintervention in those with and without heterotaxy, with each group stratified by the presence or absence of pulmonary vein obstruction (PVO). The population consisted of 118 patients with heterotaxy (of whom 49 had PVO) and 218 patients without heterotaxy (of whom 87 had PVO). Not surprisingly, the authors found that patients with heterotaxy had greater mortality than those without and that those with PVO had worse survival than those 